\title{
Motives to use Facebook and problematic Facebook use in adolescents
}

\author{
CLAUDIA MARINO $^{1,2 *}$, ELENA MAZZIERI ${ }^{3}$, GABRIELE CASELLI $^{2,4,5}$, ALESSIO VIENO $^{1}$ and MARCANTONIO M. SPADA ${ }^{2}$ \\ ${ }^{1}$ Dipartimento di Psicologia dello Sviluppo e della Socializzazione, Università degli Studi di Padova, Padova, Italy \\ ${ }^{2}$ Division of Psychology, School of Applied Sciences, London South Bank University, London, UK \\ ${ }^{3}$ Studi Cognitivi, San Benedetto del Tronto, Italy \\ ${ }^{4}$ Studi Cognitivi, Milano, Italy \\ ${ }^{5}$ Department of Psychology, Sigmund Freud University, Milano, Italy
}

(Received: September 18, 2017; revised manuscript received: January 29, 2018; accepted: March 25, 2018)

\begin{abstract}
Background and aims: There is a growing body of evidence suggesting that problematic Facebook use (PFU) is an emerging problem, particularly among adolescents. Although a number of motivations explaining why people engage in frequent Facebook use have been identified, less is known about the specific psychological needs underlying PFU. The aim of this study is to test a model designed to assess the unique contribution of psychological motives for using Facebook to the different PFU dimensions in a sample of adolescents. Methods: A total of 864 Italian adolescents participated in the study. Multivariate multiple regression was run to test whether the four motives were differently associated with problematic dimensions. Results: The results showed that the two motives with negative valence (coping and conformity) were significantly linked to the five dimensions of PFU, whereas the two motives with positive valence (enhancement and social) appeared to be weaker predictors for three out of these five dimensions. Discussion and conclusion: In conclusion, psychological motives for using Facebook appeared to significantly contribute to explaining PFU among adolescents, and should be considered by researchers and educational practitioners.
\end{abstract}

Keywords: adolescents, motives, problematic Facebook use

\section{INTRODUCTION}

There is a growing body of evidence suggesting that problematic social media use (also termed "disorder" or "addiction") is an emerging mental problem, particularly among adolescents (e.g., van den Eijnden, Lemmens, \& Valkenburg, 2016). Indeed, in the last decade, the use of social networking sites (SNSs) has been increasing worldwide with Facebook reaching two billion of users, and around one billion of daily active users as of July 2017 (Facebook, 2017). However, problematic Internet use and thus problematic social media use have not yet been recognized as mental disorders or as behavioral addictions (Carbonell \& Panova, 2017). For this reason, in this study, the term "problematic use" is preferred to "addiction" when referring to Facebook use. Despite the fact that there is still a lack of consensus about terminology and definitions for these phenomena, several researchers have agreed that Internet use, and especially social media use, can be problematic for some users (Casale \& Fioravanti, 2017).

Whereas many scholars have argued that Facebook could represent a positive tool for anxious people to increase their perceived social support (Indian \& Grieve, 2014), or for adolescents to improve their civic engagement skills (Lenzi et al., 2015), and other studies have highlighted that Facebook misuse could be associated with a wide range of negative consequences for personal psychosocial well-being among adolescents and young adults (Bányai et al., 2017; Kuss \& Griffiths, 2011; Ryan, Chester, Reece, \& Xenos, 2014). Specifically, Facebook misuse has been associated with symptomology of depression and anxiety (Andreassen, 2015; Pantic et al., 2012; Rosen, Whaling, Rab, Carrier, \& Cheever, 2013), decreased self-esteem, and low levels of life satisfaction (Satici \& Uyasal, 2015). Hence, it has been argued that problematic Facebook use (PFU) might represent an emerging mental health problem (Kuss \& Griffiths, 2011) as it is likely to create psychological, social, or school problems in people's life (Lee, Cheung, \& Thadani, 2012).

For the purpose of this study, PFU has been operationalized as a multidimensional construct, in accordance with the Internet-specific model of generalized problematic Internet use (Caplan, 2010; Marino, Vieno, Altoè, \& Spada, 2017). Indeed, it has been purported that considering different dimensions of PFU might be of value when analyzing this complex phenomenon (Marino et al., 2017). Specifically,

\footnotetext{
* Corresponding author: Claudia Marino; Dipartimento di Psicologia dello Sviluppo e della Socializzazione, Università degli Studi di Padova, via Venezia 8, Padova 35121, Italy; Phone: +39 049 827 6402; Fax: +390498276547; E-mail: claudia.marino@ phd.unipd.it
}

This is an open-access article distributed under the terms of the Creative Commons Attribution-NonCommercial 4.0 International License, which permits unrestricted use, distribution, and reproduction in any medium for non-commercial purposes, provided the original author and source are credited, a link to the CC License is provided, and changes - if any - are indicated. 
this model captures social, emotional, and behavioral aspects of PFU, which might potentially be addressed separately by scholars to understand the mechanisms underlying PFU, and by practitioners to tackle the specific user's problem related to Facebook use. Indeed, Facebook users may prefer online social interactions over a face-to-face context; they may tend to use Facebook to regulate their mood, and engage in cognitive preoccupation and compulsive use, thus experiencing negative consequences in real life, such as difficulties in managing their life or missing other important offline activities (Marino et al., 2017).

Given the possible negative impact of PFU on well-being (e.g., Satici \& Uyasal, 2015), several studies have focused on possible predictors of PFU (see "Possible predictors of PFU: Motives underlying Facebook use" section) to better understand this phenomenon and thus to build targeted prevention and intervention programs. However, there is a lack of theorydriven research on proximal antecedents that may lead to PFU among adolescents (Lee et al., 2012; Marino, Vieno, Pastore, et al., 2016). Moreover, to date, to the authors' knowledge, no study has specifically focused on explaining the different PFU dimensions separately. For this reason, this study aimed to test the unique role of theoretically driven motives for risky behaviors in explaining the five different dimensions of PFU among adolescents [i.e., preference for online social interaction (POSI), mood regulation, cognitive preoccupation, compulsive use, and negative outcomes].

\section{Possible predictors of PFU: Motives underlying Facebook use}

A large number of studies have highlighted the importance of understanding the antecedents of PFU among young people. For example, it has been showed that certain personality traits (such as neuroticism and extraversion) are significantly involved in PFU among young people (e.g., Marcial, 2013; Marino, Vieno, Pastore, et al., 2016; Tang, Chen, Yang, Chung, \& Lee, 2016) as well as self-regulation strategies (Błachnio \& Przepiorka, 2016), social influence processes (Marino, Vieno, Pastore, et al., 2016), and attachment styles (Monacis, de Palo, Griffiths, \& Sinatra, 2017).

Moreover, motivations have been among the most commonly investigated antecedents of online activities, including SNS engagement and gaming (e.g., Demetrovics et al., 2011; Joinson, 2008; Papacharissi \& Mendelson, 2011; Ryan, Rigby, \& Przybylski, 2006; for a review, see Ryan et al., 2014). In recent years, scholars have been suggesting that online activities (like videogames) "represent new ways of satisfying basic human needs within the conditions of modern society" (Demetrovics et al., 2011, p. 814). In this view, several studies identified a "pull" of motivations leading to (problematic) gaming, such as escapism, socializing, achievement, and competition (e.g., Király et al., 2015; Ryan et al., 2006). However, few studies endorsed a recognized motivational theory to explain problematic gaming (Demetrovics et al., 2011; Lafrenière, Verner-Filion, \& Vallerand, 2012), indicating the need for a theoretically based understating of the psychological motives involved in online activities (Lafrenière et al., 2012).

Similarly, with regard to Facebook use, although a number of motivations (strictly related to specific Facebook applications) have been outlined trying to explain why people engage in frequent Facebook use (e.g., selfexpression, information sharing, social connection, and using applications; Alhabash, Chiang, \& Huang, 2014; Giannakos, Chorianopoulos, Giotopoulos, \& Vlamos, 2013; Ryan et al., 2014), less is known about the specific psychological needs underlying PFU. Beyond the motivations leading to non-PFU, it has been recently argued that researchers should take a closer look at the specific motivations that are more likely to be involved in the development of PFU, such as the desire for mood modification, social facilitation, or boredom (Ryan, Reece, Chester, \& Xenos, 2016). Indeed, according to the compensatory model of Internet use (Kardefelt-Winther, 2014), users are driven to use different Internet applications, such as SNSs to escape from negative moods, or to frequent social online interactions if experiencing social anxiety (e.g., Caplan, 2010; Sheldon, 2008). From this viewpoint, one of the keys to understanding the manifestation of PFU may lie in the types of psychological motives that drive use. To date, few studies have attempted to investigate such motivations by adopting a strong theoretically based approach or simultaneously considering the role of affectivity and social needs (e.g., Marino, Vieno, Moss, et al., 2016).

For the purpose of this study, the traditional motivational model for problematic behaviors has been used (Bischof-Kastner, Kuntsche, \& Wolstein, 2014; Cox \& Klinger, 1988; Marino, Vieno, Moss, et al., 2016). According to this model, adults and adolescents' problematic behaviors are driven by certain expectations to achieve desired effects. Initially developed to understand alcohol use among adolescents (Cox \& Klinger, 1988; Mazzardis, Vieno, Kuntsche, \& Santinello, 2010), this model has been successfully adapted to several behaviors, including gambling (Canale, Vieno, Griffiths, Rubaltelli, \& Santinello, 2015), Internet use (Bischof-Kastner et al., 2014), and Facebook use (Marino, Vieno, Moss, et al., 2016). The motivational model provides for four motives for Facebook use obtained by crossing two orthogonal dimensions, that is positive or negative valence (enhancing or reducing positive or negative feelings, respectively), and internal or external source (dealing with one's own sensations or significant others, respectively). The four theoretically based motives are enhancement (positive valence and internal source; that is, to expect to improve positive affect using Facebook); social (positive valence and external source; that is, to expect to improve relationships with friends); coping (negative valence and internal source; that is, to expect to diminishing bad feelings using Facebook); and conformity (negative valence and external source; to use Facebook because of the peer pressure to use it) (Marino, Vieno, Moss, et al., 2016).

\section{Aims of the current study}

This study aims to test a model designed to assess the unique contribution of motives for using Facebook on different PFU dimensions among adolescents. The conceptual model is presented in Figure 1. While a few studies have shown that motives for Facebook use are directly associated with an overall measure of PFU (e.g., Marino, Vieno, Moss, et al., 2016), to date, no attempt has been made to examine the role 


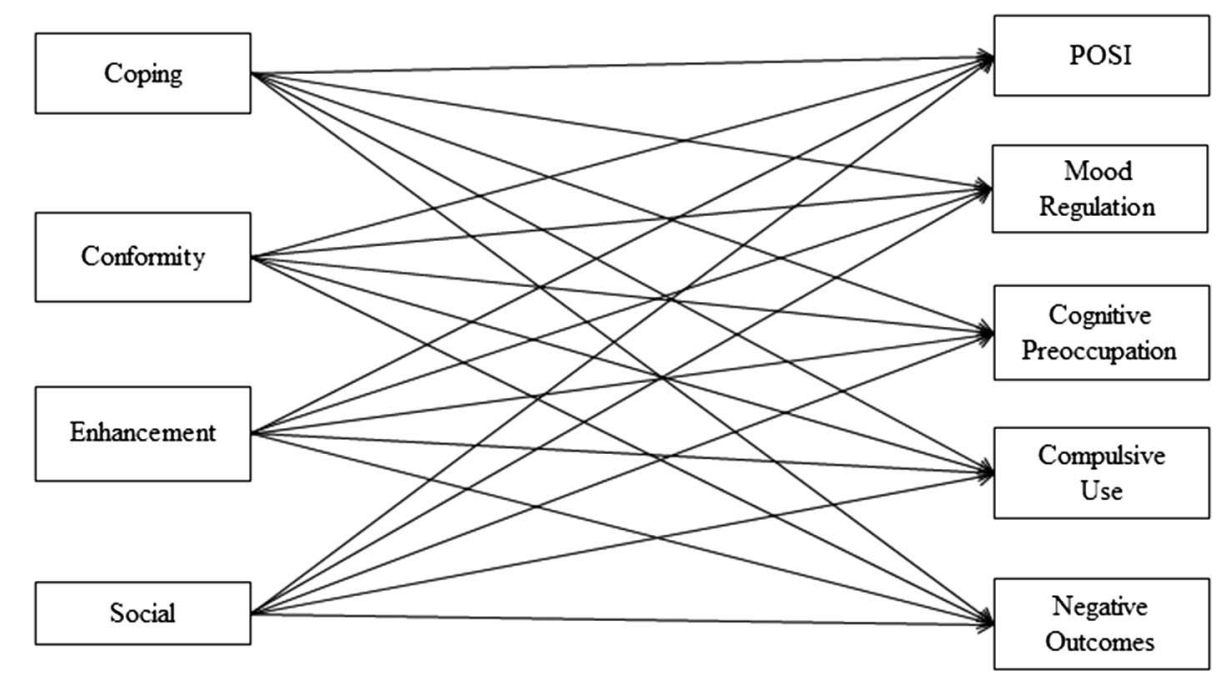

Figure 1. Proposed theoretical model predicting problematic Facebook use. Note. POSI: preference for online social interaction

of such motives in predicting the five PFU dimensions. More specifically, this study sought to test a single model in which the contribution of each motive for using Facebook would be considered above and beyond that of other motives. In other words, the aim of the study is to highlight which type of individual motive (i.e., coping, conformity, enhancement, and social) is more strictly associated with specific dimensions of PFU (i.e., POSI, mood regulation, cognitive preoccupation, compulsive use, and negative outcomes).

Although internal motives (i.e., coping and enhancement) have been found to predict generic problematic Internet use among adolescents (Bischof-Kastner et al., 2014), motives with negative valence (i.e., coping and conformity) appeared to be linked to PFU among young adults (Marino, Vieno, Moss, et al., 2016). Therefore, we tested whether such theory-driven motives are directly and differently linked to the PFU dimensions. The model was tested in a sample of adolescents, in whom social media use is spread the most and the possible negative influences of problematic social media use are expected to be worse (Valkenburg \& Peter, 2011; van den Eijnden et al., 2016).

\section{METHODS}

\section{Participants and procedure}

A convenience sample of 864 Italian adolescents from a secondary school in Italy voluntarily participated in the study and answered a paper-and-pencil questionnaire. Participants were aged between 14 and 22 years (mean age = 17.37, $S D=1.51 ; 46.7 \%$ females). Permission was sought from the Head of School and signed consent was obtained from the parents of underage students, whereas aged students gave their own written consent. All responses to the self-report instruments (outlined below) were collected during a regular school day in classrooms and in the presence of the class teacher. Eighty-four participants declared that they did not have a Facebook account and were excluded from analyses. Moreover, 10 participants with a Facebook account did not answer all the questions of interest and were excluded from the analysis. Therefore, the analyses were run on a final sample of 770 students aged between 14 and 22 years (mean age $=17.45, S D=1.49$; $46.5 \%$ females). Of them, only 10 students declared that they did not own a personal computer and 9 reported that they did not own a smartphone. The mean number of Facebook friends in this sample was about 940 friends $(S D=917$; ranging from 3 to 6,000$)$. Moreover, $85 \%$ of the adolescents reported having created their Facebook account before 14 years of age. With regard to the perceived frequency of Facebook use, $75 \%$ of the participants declared to be online from "quite" to "very" often during a standard weekday.

\section{Measures}

Problematic Facebook use. PFU was measured with the Italian version of the Problematic Facebook Use Scale (Marino et al., 2017). Participants were asked to rate the extent to which they agreed with each of the 15 items on an 8 -point scale [ranging from (1) "definitely disagree" to (8) "definitely agree"]. The scale included five subscales, of three items each: (a) POSI (e.g., "I prefer online social interaction over face-to-face communication"); (b) mood regulation (three items, e.g., "I have used Facebook to make myself feel better when I was down"); (c) cognitive preoccupation (three items, e.g., "I would feel lost if I was unable to access Facebook"); (d) compulsive use (three items, e.g., "I have difficulty controlling the amount of time I spend on Facebook"); and (e) negative outcomes (three items, e.g., "My Facebook use has created problems for me in my life"). Altogether, these factors also give an overall score of PFU. Items were averaged to obtain continuous variables for a total score of PFU and its five subscales. Higher scores on the scale and subscales indicate higher levels of PFU. The Cronbach's $\alpha$ for the scale was .85 [95\% CI: 0.83-0.86] and the Cronbach's $\alpha$ s for the 
subscales were as follows: .78 [95\% CI: 0.76-0.81] for POSI; .65 [95\% CI: 0.61-0.69] for mood regulation; .70 [95\% CI: 0.67-0.73] for cognitive preoccupation; .79 [95\% CI: 0.77-0.82] for compulsive use; and .65 [95\% CI: 0.61-0.68] for negative outcomes.

Facebook Motives Questionnaire. Motives for using Facebook were measured with an adapted version of the Internet Motives Questionnaire (Bischof-Kastner et al., 2014) to Facebook context. This adapted scale has been already used among Italian young adults and showed good validity properties (Marino, Vieno, Moss, et al., 2016). The participants were asked how often they logged on Facebook for different motivations, thinking of all the times they have been on Facebook during the past 12 months. The scale includes four motives: coping (e.g., "To forget your worries?"), conformity (e.g., "To be liked by others?"), enhancement (e.g., "Because it is exciting?"), and social motive (e.g., "To come into contact with others?"). The questionnaire contains 16 items rated on a 5-point scale [ranging from (1) "never or almost never" to (5) "always or almost always"], so that higher scores indicate higher levels on each motive. The Cronbach's $\alpha$ s for the subscales were as follows: .86 [95\% CI: 0.84-0.88] for coping; .71 [95\% CI: 0.68-0.64] for conformity; .60 [95\% CI: 0.56-0.64] for enhancement; and .79 [95\% CI: $0.77-0.82]$ for social motive.

\section{Statistical analysis}

Correlation analyses were conducted to test the associations between the variables of interest. The pattern of relationships specified by our theoretical model (Figure 1) was examined through multivariate multiple regression, using the package Lavaan (Rosseel, 2012) of the software R ( $\mathrm{R}$ Development Core Team, 2012) and utilizing a single observed score for each construct included in the model. In particular, the covariance matrix of the observed variable was analyzed with maximum likelihood method estimator. To evaluate the goodness of fit of the model, we considered the $R^{2}$ of each endogenous variable and the total coefficient of determination (TCD; Bollen, 1989; Jöreskog \& Sörbom, 1996). The TCD represents the overall effect of the independent variables on the dependent variables; in other words, the higher the TCD, the larger the explained variance. The TCD is computed as following: $1-(\mathrm{psi} / \mathrm{cov})$ (where psi represents the determinant of the covariance matrix among the errors and cov represents the determinant of the fitted covariance matrix among endogenous variables). In the tested model, the five PFU factors were the dependent variables and the four Facebook motives were the independent variables (Figure 1).

\section{Ethics}

Formal approval for this research was given by the Ethics Committee of Psychological Research at the University of Padova, Italy. All participants were informed about the study and all provided informed written consent. Parental consent was sought for those younger than 18 years of age. This study did not involve human and/or animal experimentation.

\section{RESULTS}

Table 1 shows the means, standard deviations, and bivariate correlations between the variables included in the study. As expected, all the study variables were correlated with each other. In particular, a strong positive correlation was found between the overall score of PFU and motives, and between PFU factors and motives, especially between coping motive and mood regulation. Moreover, in line with previous studies (e.g., Marino, Vieno, Pastore, et al., 2016), age and gender did not appear to be associated with overall PFU. Nevertheless, low but significant correlations were found between gender and different PFU factors and motives. Specifically, being female appeared to be associated with higher levels of cognitive preoccupation and compulsive use, whereas being male appeared to be associated with negative outcomes and two motives (i.e., conformity and social).

The theoretical model was tested including all the variable of interest. Four coefficients did not reach statistical significance and were characterized by a small effect size: the link between enhancement motive and two PFU factors (mood regulation and negative outcomes), and the relationship between social motive and two PFU factors (POSI and negative outcomes). All other coefficients were significant at least at the $p<.05$ level. As shown in Figure 2, positive associations were found between motives and PFU factors. Specifically, a strong association was found between coping and mood regulation, whereas low-to-moderate associations were found, for example, between conformity and POSI, and between enhancement and compulsive use. The lowest associations were observed between the social motive and the PFU factors.

The squared multiple correlations for the endogenous variables indicate that the model accounts for $51 \%$ of the variance of the mood regulation factor of PFU, $25 \%$ of cognitive preoccupation, $20 \%$ for compulsive use and for less variance of other factors (i.e., 13\% for negative outcomes and $12 \%$ for POSI). Finally, the total amount variance explained by the model $(\mathrm{TCD}=0.60)$ indicated a good fit to the observed data. In terms of effect size, $\mathrm{TCD}=0.60$ corresponds to a correlation of $r=.78$. According to the Cohen's (1988) traditional criteria, this is a very large effect size.

\section{DISCUSSION AND CONCLUSIONS}

The goal of this study was to examine the contribution of theory-driven motives for using Facebook to PFU dimensions among adolescents. Multivariate multiple regression revealed that all the four motives were differently associated with PFU dimensions. Specifically, the two motives with negative valence (coping and conformity) were significantly linked to all the PFU dimensions (with coping motive being the stronger predictor for mood regulation), whereas the two motives with positive valence (enhancement and social) appeared to be weaker predictors for three out of the five PFU dimensions (with negative outcomes being the lessexplained factor). These results are consistent with our 
hypotheses that motives might differently influence the different aspects of PFU and, to an extent, echo the findings from previous studies showing that Facebook (like alcohol abuse; Internet addiction or gambling) is likely to be involved in the development of problematic behaviors among the adolescents (e.g., Bischof-Kastner et al., 2014).

When considering the source axis of the motivational model, the "internal" motives (i.e., coping and enhancement) appeared to be more strongly associated with PFU outcomes than "external" motives (i.e., conformity and social). It could be argued that Facebook use may represent an easy way to regulate one's own internal states, to cope with low mood or to forget about real-life problems, and to try to experience positive emotions (Marino et al., 2017). Even if Facebook is "social" in nature, social motive appeared to be nonsignificantly linked to the POSI. A possible explanation for this result is that the need to be connected to other people on Facebook is positive per se (e.g., Ellison, Steinfield, \& Lampe, 2007), and that it might escalate into problematic use using POSIs when adolescents feel the peer pressure to use Facebook (conformity motive). This finding is consistent with results from studies showing that Facebook use can lead to worse outcomes when the group-norm about the importance of Facebook use is stronger (Marino, Vieno, Pastore, et al., 2016).

With regard to mood regulation, our findings showed that this dimension of PFU is strongly linked to coping motive. It should be noted that such strong association could be due to the similarity of the items included in the two measures to assess coping motive and mood regulation factor (e.g., "To forget your worries?" for coping motive in the Facebook Motives Questionnaire, and "I have used Facebook to make myself feel better when I was down" for mood regulation in the Problematic Facebook Use Scale). In other words, the conceptual overlapping between the two factors (coping motive and mood regulation factor) may be responsible for inflating the strength of the association. However, from a theoretical perspective, the problematic use of Facebook to modify one's own mood could be considered as a main motive and as a symptom of PFU as well. This is plausible given that using Facebook to cope with low mood or to forget about daily worries and problems may lead users to believe that they can actually satisfy the need to feel better or to find someone to talk to when feeling isolated by engaging in Facebook use. In parallel to this view, it has been argued that problematic Internet use may be conceptualized as a maladaptive cognitive-affective self-regulation strategy (Caplan, 2003, 2010; LaRose, Lin, \& Eastin, 2003; Spada, Langston, Nikčević, \& Moneta, 2008). Moreover, our results showed that, although associated with all the four motives, cognitive preoccupation and the compulsive dimension of PFU are mainly explained by coping and enhancement motives. In other words, users using Facebook mainly to cope with low mood and to enhance pleasant feelings may tend to show deficient self-regulation patterns. In fact, according to the cognitive-behavioral model of problematic Internet use (e.g., Caplan, 2010; Davis, 2001), cognitive preoccupation and compulsive use are considered as cognitive and behavioral indicators of deficient self-regulation, that is " $a$ state in which conscious self-control is relatively diminished" (LaRose et al., 2003, p. 232). Our results 


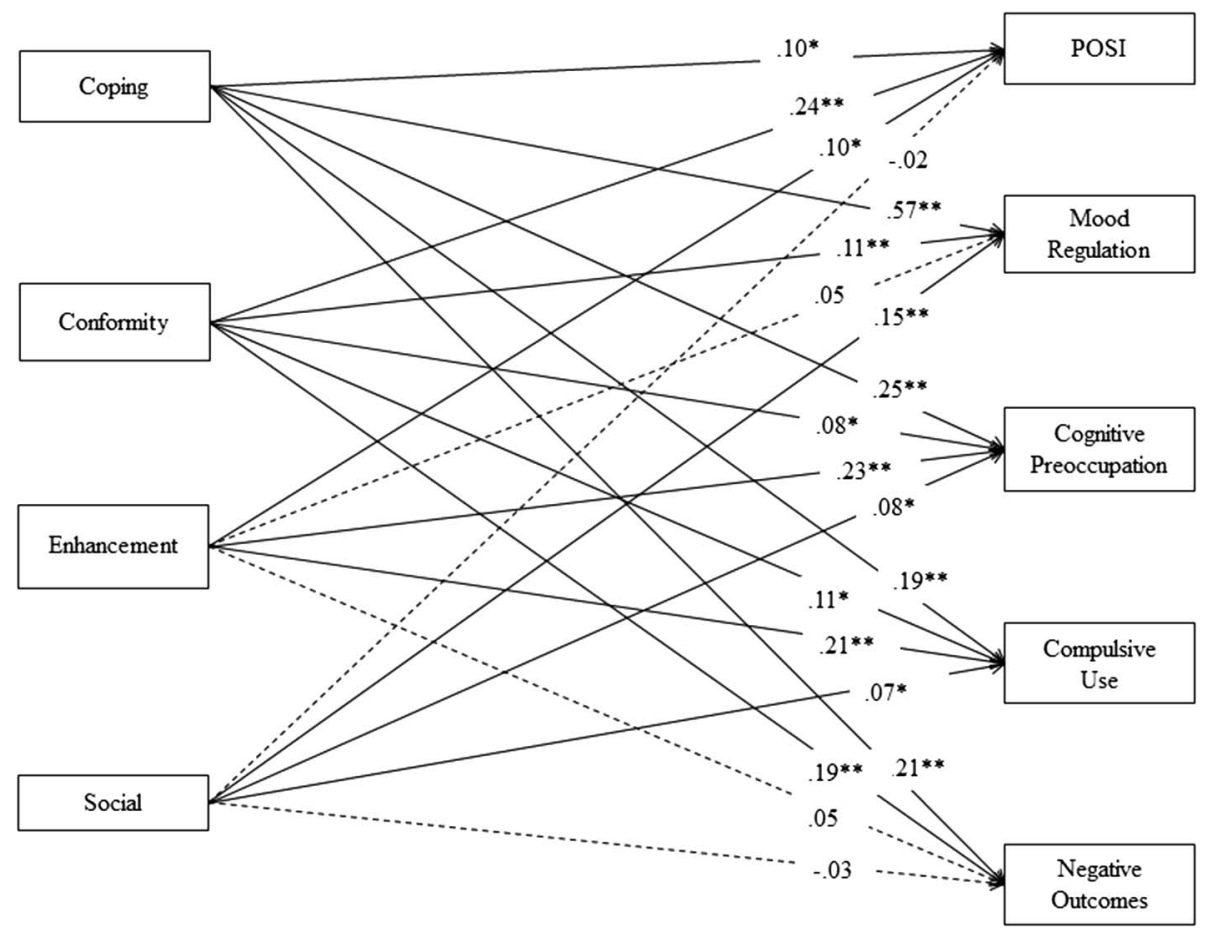

Figure 2. Tested model of the interrelationships between the study variables. Note. $N=770$. The error covariance between the independent variables was defined in the model (Grace, 2013). POSI: preference for online social interaction. ${ }^{*} p<.05 .{ }^{*} p<.01$

suggested that having strong coping and enhancement motives may lead users to obsessively think about Facebook and what is happening online, to have difficulties controlling the Facebook use and even the amount of time spent online, thus experiencing worse negative outcomes due to the engagement in such problematic behavior (Caplan \& High, 2011). With regard to the negative outcomes, our findings showed that only the motives with negative valence contribute to the explanation of problems created by Facebook for real life, supporting the argument that Facebook can constitute to a degree an easy (but problematic) way to cope with negative internal states (Marino, Vieno, Moss, et al., 2016). It can be also predicted that the four motives for Facebook use are more directly involved in the dysfunctional mechanisms of PFU (i.e., self-regulation) than the outcomes of such use, which could be considered as a result of such maladaptive dimensions of PFU.

Overall, these findings suggest that Facebook motives can constitute, to a degree, direct antecedents of each PFU dimension, thus adding to the extant literature on this topic by offering a theory-driven approach to understand why young users engage in PFU.

The present results are preliminary and some limitations must be highlighted. First, the sample was not randomly selected and the use of data from a self-report questionnaire may be influenced by recall bias and answer accuracy. Second, the cross-sectional design does not allow definitive statements about causality, even though it is well-documented that motives are often predictors for problematic behaviors.

Despite these limitations, results of this study have potentially important implications for developing prevention and intervention programs for adolescents. First, understanding the links between Facebook motives and PFU dimensions may help in increasing the knowledge on psychological mechanisms underlying problematic patterns of Facebook use among adolescents. Second, it has been recently demonstrated that targeting the motives for a given behavior is an effective way to prevent the engagement in problematic behaviors (Király et al., 2015). For example, some studies reported the efficacy of evidence-based interventions tailored to motives and beliefs to prevent alcohol abuse and to reduce problematic gambling among adolescents and young adults (Canale et al., 2016; Disperati et al., 2015). Therefore, developing interventions considering the specific motives that lead to each dimension of PFU might be of value.

In conclusion, the results from this study provide an important addition to the literature on PFU, suggesting that the motivational model (Cox \& Klinger, 1988) might be used to develop a theory-driven conceptualization of PFU.

Funding sources: No financial support was received for this study.

Authors' contribution: CM, EM, and AV are responsible for the study concept and design. CM performed the analysis. AV supervised the statistical analysis. EM and GC contributed to the interpretation of data. GC and MMS performed study supervision.

Conflict of interest: The authors declare no conflict of interest. 


\section{REFERENCES}

Alhabash, S., Chiang, Y., \& Huang, K. (2014). MAM \& U\&G in Taiwan: Differences in the uses and gratifications of Facebook as a function of motivational reactivity. Computers in Human Behavior, 35, 423-430. doi:10.1016/j.chb.2014.03.033

Andreassen, C. S. (2015). Online social network site addiction: A comprehensive review. Current Addiction Reports, 2, 175-184. doi:10.1007/s40429-015-0056-9

Bányai, F., Zsila, A., Király, O., Maraz, A., Elekes, Z., Griffiths, M. D., Andreassen, S. C., \& Demetrovics, Z. (2017). Problematic social media use: Results from a large-scale nationally representative adolescent sample. PLoS One, 12(1), e0169839. doi:10.1371/journal.pone.0169839

Bischof-Kastner, C., Kuntsche, E., \& Wolstein, J. (2014). Identifying problematic Internet users: Development and validation of the Internet Motive Questionnaire for Adolescents (IMQ-A). Journal of Medical Internet Research, 16(10), e230. doi:10. 2196/jmir.3398

Błachnio, A., \& Przepiorka, A. (2016). Dysfunction of selfregulation and self-control in Facebook addiction. Psychiatric Quarterly, 87(3), 493-500. doi:10.1007/s11126-015-9403-1

Bollen, K. A. (1989). Structural equations with latent variables. New York, NY: Wiley.

Canale, N., Vieno, A., Griffiths, M. D., Marino, C., Chieco, F., Disperati, F., Andriolo, S., \& Santinello, M. (2016). The efficacy of a web-based gambling intervention program for high school students: A preliminary randomized study. Computers in Human Behavior, 55, 946-954. doi:10.1016/j.chb.2015.10.012

Canale, N., Vieno, A., Griffiths, M. D., Rubaltelli, E., \& Santinello, M. (2015). How do impulsivity traits influence problem gambling through gambling motives? The role of perceived gambling risk/benefits. Psychology of Addictive Behaviors, 29(3), 813-823. doi:10.1037/adb0000060

Caplan, S. E. (2003). Preference for online social interaction: A theory of problematic Internet use and psychosocial well-being. Communication Research, 30(6), 625-648. doi:10. $1177 / 0093650203257842$

Caplan, S. E. (2010). Theory and measurement of generalized problematic Internet use: A two-step approach. Computers in Human Behavior, 26(5), 1089-1097. doi:10.1016/j.chb.2010.03.012

Caplan, S. E., \& High, A. C. (2011). Online social interaction, psychosocial well being, and problematic Internet use. In K. S. Young \& C. N. de Abreu (Eds.), Internet addiction: A handbook and guide to evaluation and treatment (pp. 35-53). Hoboken, NJ: Wiley.

Carbonell, X., \& Panova, T. (2017). A critical consideration of social networking sites' addiction potential. Addiction Research \& Theory, 25(1), 48-57. doi:10.1080/16066359.2016.1197915

Casale, S., \& Fioravanti, G. (2017). Shame experiences and problematic social networking sites use: An unexplored association. Clinical Neuropsychiatry, 14(1), 44-48.

Cohen, J. (1988). Statistical power analysis for behavioral science (2nd ed.). Hillsdale, NJ: Lawrence Erlbaum Associates.

Cox, W. M., \& Klinger, E. (1988). A motivational model of alcohol use. Journal of Abnormal Psychology, 97(2), 168-180. doi:10.1037/0021-843X.97.2.168

Davis, R. A. (2001). A cognitive-behavioral model of pathological Internet use. Computers in Human Behavior, 17(2), 187-195. doi:10.1016/S0747-5632(00)00041-8
Demetrovics, Z., Urbán, R., Nagygyörgy, K., Farkas, J., Zilahy, D., Mervó, B., Reindl, A., Ágoston, C., Kertész, A., \& Harmath, E. (2011). Why do you play? The development of the Motives for Online Gaming Questionnaire (MOGQ). Behavior Research Methods, 43(3), 814-825. doi:10.3758/s13428-011-0091-y

Disperati, F., Canale, N., Vieno, A., Marino, C., Chieco, F., Andriolo, S., \& Santinello, M. (2015). "Which type of drinker are you?": An online prevention programme to reduce alcohol consumption and alcohol related problems. Giornale Italiano di Psicologia, 42(1-2), 289-302.

Ellison, N. B., Steinfield, C., \& Lampe, C. (2007). The benefits of Facebook 'friends': Social capital and college students' use of online social network sites. Journal of Computer-Mediated Communication, 12(4), 1143-1168. doi:10.1111/j.1083-6101. 2007.00367.x

Facebook. (2017). Facebook newsroom: Company info. Retrieved from https://newsroom.fb.com/company-info/. Accessed on: July 19, 2017.

Giannakos, M. N., Chorianopoulos, K., Giotopoulos, K., \& Vlamos, P. (2013). Using Facebook out of habit. Behaviour \& Information Technology, 32(6), 594-602. doi:10.1080/ 0144929X.2012.659218

Grace, J. B. (2013). Basic lavaan syntax guide. Retrieved from http://www.structuralequations.com/resources/Basic_lavaan_ Syntax_Guide_Aug1_2013.pdf. Accessed on: January 24, 2018.

Indian, M., \& Grieve, R. (2014). When Facebook is easier than face-to-face: Social support derived from Facebook in socially anxious individuals. Personality and Individual Differences, 59, 102-106. doi:10.1016/j.paid.2013.11.016

Joinson, A. N. (2008, April). Looking at, looking up or keeping up with people?: Motives and use of facebook. In Proceedings of the SIGCHI conference on Human Factors in Computing Systems (pp. 1027-1036). Florence, Italy: ACM.

Jöreskog, K. G., \& Sörbom, D. (1996). LISREL 8: User's reference guide. Chicago, IL: Scientific Software International.

Kardefelt-Winther, D. (2014). A conceptual and methodological critique of internet addiction research: Towards a model of compensatory Internet use. Computers in Human Behavior, 31, 351-354. doi:10.1016/j.chb.2013.10.059

Király, O., Urbán, R., Griffiths, M. D., Ágoston, C., Nagygyörgy, K., Kökönyei, G., \& Demetrovics, Z. (2015). The mediating effect of gaming motivation between psychiatric symptoms and problematic online gaming: An online survey. Journal of Medical Internet Research, 17(4), e88. doi:10.2196/jmir.3515

Kuss, D. J., \& Griffiths, M. D. (2011). Addiction to social networks on the Internet: A literature review of empirical research. International Journal of Environment and Public Health, 8(9), 3528-3552. doi:10.3390/ijerph8093528

Lafrenière, M. A. K., Verner-Filion, J., \& Vallerand, R. J. (2012). Development and validation of the Gaming Motivation Scale (GAMS). Personality and Individual Differences, 53(7), 827-831. doi:10.1016/j.paid.2012.06.013

LaRose, R., Lin, C. A., \& Eastin, M. S. (2003). Unregulated Internet usage: Addiction, habit, or deficient self-regulation? Media Psychology, 5(3), 225-253. doi:10.1207/S1532785 XMEP0503_01

Lee, Z. W. Y., Cheung, C. M. K., \& Thadani, D. R. (2012). An investigation into the problematic use of Facebook. Proceedings of the 45th Hawaii International Conference on System Sciences, Maui, HI, USA, 1768-1776. 
Lenzi, M., Vieno, A., Altoè, G., Scacchi, L., Perkins, D. D., Zukauskiene, R., \& Santinello, M. (2015). Can Facebook informational use foster adolescent civic engagement? American Journal of Community Psychology, 55(3-4), 444-454. doi:10.1007/s10464-015-9723-1

Marcial, D. E. (2013). Are you a Facebook addict? Measuring Facebook addiction in the Philippine University. International Proceedings of Economics Development and Research, 66, 12.

Marino, C., Vieno, A., Altoè, G., \& Spada, M. M. (2017). Factorial validity of the Problematic Facebook Use Scale for adolescents and young adults. Journal of Behavioral Addictions, 6(1), 5-10. doi:10.1556/2006.6.2017.004

Marino, C., Vieno, A., Moss, A. C., Caselli, G., Nikčević, A. V., \& Spada, M. M. (2016). Personality, motives and metacognitions as predictors of problematic Facebook use in university students. Personality and Individual Differences, 101, 70-77. doi:10.1016/j.paid.2016.05.053

Marino, C., Vieno, A., Pastore, M., Albery, IP., Frings, D., \& Spada, M. M. (2016). Modeling the contribution of personality, social identity and social norms to problematic Facebook use in adolescents. Addictive Behaviors, 63, 51-56. doi:10.1016/j. addbeh.2016.07.001

Mazzardis, S., Vieno, A., Kuntsche, E., \& Santinello, M. (2010). Italian validation of the Drinking Motives Questionnaire revised short form (DMQ-R SF). Addictive Behaviors, 35(10), 905-908. doi:10.1016/j.addbeh.2010.05.002

Monacis, L., de Palo, V., Griffiths, M. D., \& Sinatra, M. (2017). Social networking addiction, attachment style, and validation of the Italian version of the Bergen Social Media Addiction Scale. Journal of Behavioral Addictions, 6(2), 178-186. doi:10.1556/2006.6.2017.023

Pantic, I., Damjanovic, A., Todorovic, J., Topalovic, D., Bojovic-Jovic, D., Ristic, S., \& Pantic, S. (2012). Association between online social networking and depression in high school students: Behavioral physiology viewpoint. Psychiatria Danubina, 24(1), 90-93.

Papacharissi, Z., \& Mendelson, A. (2011). Toward a new(er) sociability: Uses, gratifications and social capital on Facebook. In S. Papathanassopoulos (Ed.), Media perspectives for the 21st century (pp. 212-230). Oxon, UK: Routledge.

$\mathrm{R}$ Development Core Team. (2013). R: A language and environment for statistical computing [Computer software manual]. Vienna, Austria. Retrieved from http://www.R-project.org/
Rosen, L. D., Whaling, K., Rab, S., Carrier, L. M., \& Cheever, N. A. (2013). Is Facebook creating "iDisorders"? The link between clinical symptoms of psychiatric disorders and technology use, attitudes and anxiety. Computers in Human Behavior, 29(3), 1243-1254. doi:10.1016/j.chb. 2012.11.012

Rosseel, Y. (2012). Lavaan: An R package for structural equation modeling. Journal of Statistical Software, 48(2), 1-36. doi:10.18637/jss.v048.i02

Ryan, T., Chester, A., Reece, J., \& Xenos, S. (2014). The uses and abuses of Facebook: A review of Facebook addiction. Journal of Behavioral Addictions, 3(3), 133-148. doi:10.1556/ JBA.3.2014.016

Ryan, T., Reece, J., Chester, A., \& Xenos, S. (2016). Who gets hooked on Facebook? An exploratory typology of problematic Facebook users. Cyberpsychology, 10(3), article 4. doi:10.5817/CP2016-3-4

Ryan, R. M., Rigby, C. S., \& Przybylski, A. (2006). The motivational pull of video games: A self-determination theory approach. Motivation and Emotion, 30(4), 344-360. doi:10.1007/ s11031-006-9051-8

Satici, S. A., \& Uysal, R. (2015). Well-being and problematic Facebook use. Computers in Human Behavior, 49, 185-190. doi:10.1016/j.chb.2015.03.005

Sheldon, P. (2008). Student favorite: Facebook and motives for its use. Southwestern Mass Communication Journal, 23(2), $39-53$.

Spada, M. M., Langston, B., Nikčević, A. V., \& Moneta, G. B. (2008). The role of metacognitions in problematic Internet use. Computers in Human Behavior, 24(5), 2325-2335. doi:10.1016/ j.chb.2007.12.002

Tang, J. H., Chen, M. C., Yang, C. Y., Chung, T. Y., \& Lee, Y. A. (2016). Personality traits, interpersonal relationships, online social support, and Facebook addiction. Telematics and Informatics, 33(1), 102-108. doi:10.1016/j.tele.2015.06.003

Valkenburg, P. M., \& Peter, J. (2011). Adolescents' online communication: An integrated model of its attraction, opportunities, and risks. Journal of Adolescent Health, 48(2), 121-127. doi:10.1016/j.jadohealth.2010.08.020

van den Eijnden, R. J., Lemmens, J. S., \& Valkenburg, P. M. (2016). The Social Media Disorder Scale: Validity and psychometric properties. Computers in Human Behavior, 61, 478-487. doi:10.1016/j.chb.2016.03.038 